\title{
Karl Polanyi e o "Grande Debate" entre substantivistas e formalistas na antropologia econômica ${ }^{1}$
}

\author{
Nuno Miguel Cardoso Machado ${ }^{2}$
}

\section{Resumo}

Na raiz do pensamento Polanyiano, encontra-se a distinção entre economia no sentido substantivo e economia no sentido formal. Com efeito, a concepção substantivista - que define a economia como um processo instituído de interação entre o homem e o ambiente natural e social que o rodeia e resulta em contínua oferta de meios para satisfazer as necessidades humanas - constitui a base do método preconizado pelo autor: a análise institucional. Com tal distinção, Polanyi (1977a) pretende evitar a "falácia economicista" que consiste na identificação automática da economia com sua forma de mercado. Ao contrário, só na moderna economia capitalista é que um "sistema de mercados formadores de preços" desempenha papel fundamental. Essas questões foram alvo de um "Grande Debate" entre as correntes substantivista - encabeçada por Polanyi - e formalista no contexto da disciplina da Antropologia Econômica.

Palavras-chave: Polanyi, Karl, 1886-1964; Substantivismo; Formalismo; Análise institucional; Economia; Mercado.

\section{Abstract}

Karl Polanyi and the "Great Debate" between the substantivists and formalists in economic anthropology

At the root of Polanyian thought, a distinction can be found between the substantive and formal concepts of the economy. In fact, the substantivist conception, that defines the economy as an instituted process of interaction between man and its natural and social environment, which results in a continuous supply of material means to meet human needs, constitutes the basis of the method recommended by the author: institutional analysis. With this distinction, Polanyi intends to avoid the "economistic fallacy", which consists of the automatic identification of the economy in its market form. Only in the modern capitalist economy does a system of "price-making markets" play a fundamental role. These questions were amply discussed in the so-called "Great Debate" between the substantivist and formalist schools of thought in the discipline of Economic Anthropology.

Keywords: Polanyi, Karl, 1886-1964; Substantivism; Formalism; Institutional analysis; Economy; Market.

JEL A12, B31, P51, Z13.

\section{0 "grande debate" substantivista/formalista}

$\mathrm{Na}$ base do pensamento Polanyiano, encontra-se a distinção entre as definições substantiva e formal da economia. Com efeito, a concepção

(1) Trabalho recebido em 11 de abril de 2010 e aprovado em 14 de fevereiro de 2011.

(2) Bolsista de Investigação no Socius - Centro de Investigação em Sociologia Econômica e das Organizações, Lisboa, Portugal. E-mail: nuno.miguel.machado@netvisao.pt. 
substantivista que define a economia como um processo instituído de interação entre o homem e o ambiente natural e social que o rodeia, o qual resulta em contínua oferta de meios para satisfazer as necessidades humanas, segundo Polanyi (1968a), constitui o fundamento do método preconizado pelo autor: a análise institucional (Stanfield, 1986).

Com essa distinção, Polanyi (1977a) pretende evitar a "falácia economicista", ou seja, a identificação automática da economia com sua forma de mercado. Ao contrário, só na moderna economia capitalista é que um "sistema de mercados formadores de preços" desempenha papel fundamental. Tais questões foram alvo de um "Grande Debate" entre as correntes substantivista - encabeçada por Polanyi - e formalista no contexto da disciplina da Antropologia Econômica (cf. Elardo, 2003).

Como nota, Humphreys (1969, p. 196):

A parte da teoria de Polanyi que tem atraído as maiores críticas é sua assunção de que a teoria econômica moderna não pode ser utilizada para analisar $o$ funcionamento das economias primitivas e, relacionado a isso, o argumento de que a economia (economy) possui dois significados, o formal e o substantivo, que apenas coincidem na moderna economia de mercado.

Se essa questão/problemática teve sua origem nas décadas de 1930 e 1940 com autores como Malinowski, Firth, Herskovits, Knight ou Goodfellow, apenas nos anos 1950, 1960 e 1970 seria objeto de um debate bastante alargado e acérrimo entre as duas correntes no contexto da antropologia econômica. Tratouse, na prática, do denominado "Grande Debate" entre substantivistas e formalistas, o qual sofreu talvez um impulso decisivo com a publicação do artigo seminal de Karl Polanyi intitulado "The Economy as Instituted Process" e da obra Trade and markets in the early empires, editada por Polanyi, Arensberg e Pearson (1957). Assim, Polanyi deve ser inserido e suas contribuições entendidas, no contexto específico de um debate decisivo sobre as bases metodológicas da disciplina da antropologia econômica.

A discussão girou em torno da possibilidade de utilização e aplicação da moderna teoria econômica para estudar e analisar as economias do passado, isto é, de sua pretensa aplicabilidade universal enquanto base explicativa da realidade. Os substantivistas, encabeçados por Polanyi (cf. 1968a; 1968b; 1977a; 1977b; Polanyi et al., 1968), defendiam que o esquema formalista - assente no modelo neoclássico da teoria econômica - apenas é aplicável ao estudo das modernas economias capitalistas, em que os mercados formadores de preços desempenham 
um papel fulcral ${ }^{3}$. Ao invés disso, deve-se partir da definição substantiva que encara a economia como um processo instituído de interação entre o homem e seu ambiente, resultando em contínua oferta de meios materiais para satisfazer suas necessidades, esta sim, com carácter universal. Entre eles, encontramos autores que contribuíram para a obra Trade and markets in the early mpires: Hopkins (cf. 1957), Pearson (cf. 1957a; 1957b), Fusfeld (cf. 1957) e Arensberg (cf. 1957). Outro autor importante é George Dalton (cf. 1961; 1962; 1965; 1967; 1968a; 1968b;1969; 1990), considerado quase consensualmente o representante por excelência da "escola Polanyiana" e aquele que mais contribuiu para desenvolver o trabalho iniciado pelo próprio Karl Polanyi. Deve-se ainda ressaltar Marshall Sahlins (cf. 2004) que, embora não se tratando do substantivista mais "puro", obteve uma grande relevância no campo da antropologia com a utilização de conceitos e instrumentos "importados" de Polanyi, como são os casos das "formas de integração".

O campo formalista, por seu turno, defende que o comportamento humano maximizador traduzido na afetação de recursos escassos a fins alternativos, isto é, a "economização", encontra-se em todas as sociedades humanas. Assim os princípios da ciência econômica moderna são passíveis de aplicação ao estudo de todas as sociedades, incluindo as do passado. Entre os autores que se destacaram nesse campo, encontramos Burling (cf. 1968), LeClair (cf. 1968), Cook (cf. 1966; 1969) e Cancian (cf. 1968).

Vários autores procuraram sintetizar e recolher os argumentos de cada um dos lados da polêmica (cf. Kaplan, 1968; Edel, 1969; Dowling, 1979; Orlove, 1986; del Toro, 1999; Elardo, 2003; Hart, Hann, 2006; Elardo, 2007a) a qual acabou, contudo, desvanecendo-se nos anos 1980 e 1990 sem que nenhum dos campos pudesse reclamar vitória (cf. Dalton, 1990; Dowling, 1979; Hart e Hann, 2006), ou seja, sem chegar-se a uma conclusão definitiva sobre quais as bases metodológicas e teóricas em que deve assentar a antropologia econômica.

Referindo-se ao campo substantivista/institucionalista, o autor que mais vem-se destacando nos últimos anos na defesa de seus princípios e visões, isto é, da análise da economia enquanto processo instituído, tem sido o economista norteamericano James R. Stanfield (cf. 1980; 1981; 1982; 1986; 1990; Stanfield, Carroll, 2003; Stanfield et al., 2006), assumida e decisivamente influenciado por

(3) E, mesmo nesse caso, Polanyi mostra algumas reservas: "Até no que se refere ao sistema de mercado em si mesmo, o mercado enquanto único quadro de referência está cada vez mais ultrapassado. Todavia, (...) o mercado não pode ser superado enquanto quadro geral de referência a não ser que as Ciências Sociais sejam bem sucedidas em desenvolver um quadro de referência mais vasto, ao qual seja o próprio mercado referenciável. Esta é, com efeito, a maior tarefa intelectual dos nossos dias no campo dos estudos econômicos. (...) tal estrutura conceptual terá de ser alicerçada no significado substantivo da economia" (Polanyi, 1968a, p. 174). 
Karl Polanyi. Também, Justin Elardo ${ }^{4}$ (cf. 2003; 2007a; 2007b; Elardo e Campbell, 2006) publicou, recentemente, algum material do ponto vista institucionalista inspirado, em parte, pelo trabalho de Karl Polanyi.

Apesar do "arrefecimento" do debate, continua-se pensando que essas questões e problemáticas mantêm toda a sua relevância e atualidade e que a perspectiva substantivista tem bastante para oferecer - em termos concetuais e metodológicos - às Ciências Sociais em geral. A visão substantivista da economia reveste ainda importância maior se for observado o crescente clima de descontentamento e contestação face à hegemonia do mercado, quer enquanto visão/paradigma (explicativo) dominante, quer enquanto realidade econômica e social nas sociedades contemporâneas. Se pretendermos melhorar nosso futuro, é necessário compreender o passado, algo atualmente bastante complicado pelo seguinte:

A maior parte dos textos contemporâneos sobre a história das "doutrinas" [econômicas] julgam e classificam os trabalhos do passado de acordo com o grau em que estes antecipam o presente (...) Sob tal ponto de vista largamente partilhado, a história do pensamento econômico torna-se uma crônica de erros e de aproximações (near-misses) em espécie de odisseia à medida que a disciplina (profession) segue o seu caminho gradualmente em direção à Terra Prometida - na prática, a ciência econômica dos últimos cinquenta anos (Heilbroner, 1979, p. 192).

Foi esse tipo de concepção que Polanyi procurou combater nas Ciências Sociais, História, Antropologia e Ciência Econômica, preconizando, ao invés, uma visão substantiva sobre as economias empíricas em todas as disciplinas encarregadas de seu estudo.

\section{Os precursores do "Grande Debate"}

\subsection{Bronislaw Malinowski}

Em geral, a obra de Malinowski (1968) constitui, na literatura, o início da antropologia econômica enquanto disciplina, conforme del Toro (1999), Elardo (2003); Hart e Hann, (2006). O valor da mesma deve-se à novidade que representaram na época suas investigações empíricas no terreno e a seu interesse sobre as relações estabelecidas entre a economia e os outros aspectos do sistema social (del Toro, 1999, p. 84; Elardo, 2003, p. 10).

(4) Em um dos trabalhos mais interessantes e importantes dos últimos anos no que concerne à polêmica substantivismo/formalismo, Elardo (cf. 2003) faz uma apresentação e revisão histórica do "Grande Debate". Seu argumento é que, se a estrutura matemática do modelo formal neoclássico for modificada de modo a responder a qualquer das três das principais críticas substantivistas sobre as suas assunções - inclusão das instituições, escolha não regulada pela escassez, cooperação ao invés de uma ação individual isolada - então, a representação do comportamento humano mudará e, com isso, a natureza do paradigma será fundamentalmente diferente, pelo que já não estaremos na presença do paradigma neoclássico (Elardo, 2003, p. 8-9).

168 Economia e Sociedade, Campinas, v. 21, n. 1 (44), p. 165-195, abr. 2012. 
Uma das principais contribuições de Malinowski (1968) ${ }^{5}$ foi a documentação e análise que efetuou do sistema de troca que existe entre os habitantes das Ilhas Trobriand, referindo-se a esse sistema como o circuito Kula. Ao descrever o circuito Kula, estava interessado em compreender as estruturas institucionais que regulavam a vida e a economia "primitivas". Em seu entender, a propensão dos Trobrianders para transferir bens sob a forma de dádivas refuta qualquer ideia acerca de um "homem econômico universal". Assim, procurou demonstrar que um sistema complexo de comércio poderia ser organizado sem a existência de mercados, dinheiro ou estados e na base da generosidade, não da ganância (Elardo, 2003, p. 10-11; Hart; Hann, 2006).

Em suma, Malinowski desafia a noção de que os povos primitivos comportam-se de acordo com os preceitos do homo economicus:

Outra noção que deve ser desfeita (exploded), de uma vez por todas, é aquela acerca de um Homem Econômico Primitivo (...) guiado em todas as suas ações por uma concepção racionalista de interesse próprio (...). O Trobriander primitivo (...) contradiz essa teoria falaciosa. Ele trabalha guiado por motivos de natureza social e tradicional altamente complexos e com vista a objetivos que não estão diretamente direcionados para a satisfação de suas necessidades presentes ou para assegurar [quaisquer outros] objetivos utilitários (Malinowski, 1968, p. 19).

O utilitarismo, portanto, tal como é usado na teoria econômica, não é apropriado para a compreensão das características culturais e institucionais da vida econômica nas Ilhas Trobriand e, por conseguinte, das economias primitivas em geral. As convenções e restrições sociais bem como os princípios da estrutura social ditam uma boa parte do comportamento econômico dos indivíduos (Elardo, 2003, p. 15; del Toro, 1999, p. 84-86).

A perspectiva de Malinowski realça tanto a importância social do indivíduo como a relevância das instituições enquanto força motriz da vida social e econômica. Se alguns autores concordaram com grande parte das ideias de Malinowski, outros as criticaram abertamente, pelo que emergiu um debate teórico na antropologia econômica no seguimento dos conceitos que empregou em suas análises (Elardo, 2003, p. 15-16).

\subsection{Raymond Firth}

Um dos primeiros autores a criticar Malinowski foi Raymond Firth $(1968)^{6}$, responsável pelo início do que viria a ser conhecido como a perspectiva

(5) O autor dedicou grande parte de seus esforços para analisar os habitantes das Ilhas Trobriand. Destacam-se duas obras fundamentais: em Argonauts of the Western Pacific (1922) são estudadas as trocas (exchange), enquanto Coral Gardens and Their Magic (1935) é dedicado ao estudo do trabalho, da tecnologia e da propriedade.

(6) Firth é responsável, entre outras numerosas contribuições, pela edição da importante obra formalista intitulada Themes in Economic Anthropology (1967).

Economia e Sociedade, Campinas, v. 21, n. 1 (44), p. 165-195, abr. 2012. 
formalista na antropologia econômica. Firth discordava do papel atribuído à sociedade como força determinante. Ao invés disso, é o conjunto de ações e relações que se estabelecem entre os atores individuais que constitui a preocupação de Firth, o qual pode ser definido como um individualista metodológico. Nesse sentido, encara a teoria econômica mainstream como adequada para servir de base à condução de estudos antropológicos, pois ela descreve as condições universais do comportamento humano em termos econômicos (Elardo, 2003, p. 16-17; Hart; Hann, 2006; del Toro, 1999, p. 89-91).

Em suma,

O conceito básico da ciência econômica é a afetação de recursos escassos entre várias necessidades humanas realizáveis, com o reconhecimento das alternativas que são possíveis em cada esfera. Não importa como é definida, a ciência econômica lida com as implicações das escolhas humanas, com os resultados das suas decisões. Escolhas, necessidades e suas implicações na ação envolvem relações pessoais, relações sociais. Se a antropologia social examina formas de relações sociais nas sociedades mais primitivas, a ciência econômica examina certos tipos de relações sociais - por exemplo, relações de produção e de troca - em todas as sociedades (...) Na medida em que a ciência econômica aplica princípios verdadeiramente universais, pode ser mais justificável chamá-la ciência do homem do que à antropologia, que pode ser designada como a ciência dos tipos de homens (Firth, 1968, p. 67).

Ao invés de procurar desenvolver, portanto, novos princípios econômicos, o antropólogo deve utilizar as ferramentas (universais) existentes e aplicá-las a condições sociais e culturais específicas, ou seja, "a sua tarefa [dos antropólogos] é examinar como esses princípios econômicos funcionam em contextos sociais e culturais específicos. (...) O problema do antropólogo, portanto, consiste em aplicar ou traduzir os princípios econômicos em novos contextos" (Firth, 1968, p. 65).

Pode-se concluir que, quanto a pessoas que escolhem de acordo com suas preferências, permitindo serem essas preferências e constrangimentos moldados institucionalmente, a ciência econômica neoclássica é aplicável ao "problema econômico" de qualquer sociedade (Elardo, 2003, p. 19; del Toro, 1999, p. 89).

Existem, então, várias diferenças importantes entre as ideias de Firth e de Malinowski. Foram as mesmas que abriram caminho ao debate acérrimo dos anos 1950, 1960 e 1970 no campo da antropologia econômica.

\section{Karl Polanyi e as definições substantiva e formal da economia}

\subsection{A relação entre a antropologia econômica e os sistemas econômicos comparados}

Concorda-se plenamente com Stanfield (1986, p. 26), quando afirma que "a obra de Polanyi, em traços largos, pode ser descrita como tendo sido motivada 
por duas preocupações principais: uma concernente ao problema geral da metodologia e, outra, relacionada com um problema histórico da economia política". Com efeito, o trabalho de Polanyi faz parte de um movimento mais vasto, comumente identificado como sociologia econômica.

Nesse sentido, como nota Harry Pearson (1957a, p. 307):

O ímpeto para os esforços atuais no sentido de uma sociologia econômica vem do aumento dos problemas empíricos encontrados por todos os cientistas sociais que têm de analisar as economias enquanto sistemas sociais. Os problemas levantam-se em duas áreas diferentes; aquelas que envolvem economias pré-mercantis e aquelas onde o padrão contemporâneo de um sistema de mercados autorregulados enquanto ponto de partida da análise - coloca um problema. As tentativas para lidar sistematicamente com tais problemas empíricos distintos convergem em interesse comum: o estabelecimento de uma teoria da organização econômica e do desenvolvimento genericamente relevante.

O ânimo metodológico de Polanyi deriva de seu reconhecimento da afinidade teórica fundamental que se estabelece entre a antropologia econômica e os sistemas econômicos comparados, até porque, de acordo com Dalton (1968a, p. xxxviii):

Uma das peculiaridades da antropologia econômica é que nem os fatos nem as visões sobre a vida econômica primitiva estão em falta. O registo etnográfico é enorme e detalhado. O que falta é uma abordagem teórica útil, capaz de organizar as muitas referências descritivas [da realidade].

Assim, uma teoria para a antropologia econômica é possível apenas se o programa de investigação das economias sociais primitivas e arcaicas fizer parte dos sistemas econômicos comparados. As características diferenciadoras de um sistema socioeconômico emergem apenas mediante uma análise comparativa que possibilite a especificação das peculiaridades de um determinado sistema por oposição àquelas dimensões que partilha com outras formações socioeconômicas, conforme Stanfield (1986, p. 27-28; 1990, p. 199). Isso porque:

Apenas escutando as vozes do passado no âmbito de seus próprios contextos sociais e políticos e dando (o respetivo) crédito às suas intenções e às "verdades" tais como eram percepcionadas - independentemente do fato de gostarmos ou não de escutar o que elas disseram e daquilo em que acreditavam - poderemos aproximar-nos de uma compreensão do que realmente aconteceu, embora nossas respostas sejam parciais e provisórias (Knowles, 2000, p. 30).

Pode-se afirmar que há muito para ser aprendido por meio da comparação das economias sociais primitivas e modernas se a hipersimplificação e a negligência dos contextos culturais concretos forem evitadas. Polanyi procurou ultrapassar essa visão limitada com o estabelecimento de uma ligação entre a história econômica e a antropologia social. A história das economias précapitalistas constitui, portanto, área vital para a comparação de sistemas 
econômicos, pois a negligência da dimensão histórica e totalidade cultural do comportamento humano é reconhecida como limitação central da abordagem formal (Stanfield, 1980, p. 596; 1990, p. 199-200).

A estreiteza da teoria econômica moderna - com a noção prevalecente de um comportamento econômico calculista e orientado para o ganho generalizável pode ser superada apenas por meio da disponibilidade de uma base empírica mais alargada, mediante a integração da antropologia, história e sistemas econômicos comparados em uma história econômica geral ou universal bastante compreensiva. (Stanfield, 1986, p. 32-33).

\subsection{Os dois significados da economia}

Com vista a desenvolver as citadas preocupações metodológicas, o autor distinguiu frequentemente entre dois significados para o termo economia. Como afirma Polanyi (1977b, p. 19):

Um simples reconhecimento do qual devem partir todas as tentativas de clarificação do lugar ocupado pela economia (economy) na sociedade é o fato de o termo econômico (economic) - como é usualmente utilizado para descrever um tipo de atividade humana - ser um compósito de dois significados. Estes possuem origens separadas, independentes uma da outra.

Assim, o significado substantivo deriva da dependência do homem relativamente à Natureza e a seus congêneres para assegurar a sobrevivência, ou seja, refere-se ao intercâmbio com seu ambiente natural e social mediante o qual the são fornecidos os elementos materiais necessários para a satisfação das próprias necessidades, conforme Polanyi (1968a, p. 139). Aponta para o fato elementar de que os seres humanos, tais como todos os outros seres vivos, não podem existir por qualquer período de tempo sem um ambiente físico que os sustenha (Polanyi, 1977b, p. 19).

Por seu turno, o significado formal deriva do carácter lógico da relação meios/fins, referindo-se a uma determinada situação de escolha, nomeadamente, aquela entre diferentes usos possíveis de um conjunto de meios induzida por uma insuficiência de tais meios de acordo com Polanyi (1968a, p. 140). Desse sentido, deriva a definição de escassez da ciência econômica. Nele, encontra-se subjacente o verbo maximizar ou economizar, isto é, fazer o melhor possível com os meios que se possui (Polanyi, 1977b, p. 20).

Os dois significados de economia não possuem nada em comum. Enquanto o formal resulta da lógica, o substantivo resulta dos fatos; as regras do primeiro são as da mente, as do segundo são as da natureza. O significado substantivo não implica em escolha(s) ou em insuficiência dos meios; a subsistência (livelihood) do homem pode ou não envolver a necessidade de 
escolha e, mesmo em sua presença, esta não tem de ser, forçosamente, induzida pelos efeitos limitativos de uma escassez dos meios. (Polanyi, 1968a, p. 140).

Polanyi (1977b, p. 20) chama à atenção para o fato de que "as necessidades a serem satisfeitas não são exclusivamente corporais, tais como a alimentação ou a habitação (...) pois tal restringiria absurdamente a esfera da economia". Procurando ultrapassar uma visão redutora decorrente de uma certa ambiguidade semântica, o autor faz a afirmação:

Os meios, não as necessidades, são materiais. Quer se trate de objetos úteis solicitados para evitar a fome ou necessários para fins educativos, militares ou religiosos é irrelevante. Enquanto as necessidades dependerem de objetos materiais para a sua satisfação, a referência é econômica (Polanyi, 1977b, p. 20).

Nesse sentido, estudar a sobrevivência (livelihood) humana é, para Polanyi, estudar a economia no sentido substantivo do termo. Apenas tal significado é capaz de providenciar os conceitos solicitados pelas Ciências Sociais para uma investigação de todas as economias do passado e do presente. Com efeito, o principal obstáculo encontrado prende-se com a utilização de um conceito de economia que une os dois sentidos de forma "ingênua", fundindo-se os significados de "subsistência" e "escassez" sem se perceber os perigos que isso representa para um pensamento claro e compreensivo da realidade (Polanyi, 1968a, p. 140-141).

Assim, acontece o seguinte:

Ligar a satisfação das necessidades materiais à escassez e ao ato economizador, fundindo-os em um único conceito, pode parecer justificável e razoável sob um sistema de mercado, onde e quando prevalece. Aceitar, contudo, esse conceito composto de "meios materiais escassos e de economização" como um genericamente válido aumenta a dificuldade em se conseguir desalojar a falácia economicista (economistic fallacy) da posição estratégica que ainda ocupa no pensamento contemporâneo (Polanyi, 1977b, p. 20).

\subsection{A "falácia economicista"}

Em poucas palavras, para Polanyi (1968a, p. 142), a falácia economicista "consiste na identificação artificial da economia com a sua forma de mercado". A falácia é, em si mesma, bem evidente: o aspecto físico das necessidades do homem é parte integrante da condição humana; sociedade alguma pode existir caso não possua qualquer tipo de economia substantiva. O mecanismo oferta/procura/preço, ademais, (a que em geral se chama de mercado), é uma instituição relativamente moderna com uma estrutura específica. Assim, cingir a esfera do econômico de maneira específica aos fenômenos de mercado é eliminar a maior parte da história humana de cena. Por outro lado, alargar o conceito de mercado até que abranja os fenômenos econômicos é investir artificialmente todos os aspectos econômicos 
com características peculiares que acompanham o fenômeno do mercado (capitalista) (Polanyi, 1977a, p. 6).

Pode-se afirmar que a economia de mercado criou um novo tipo de sociedade. O sistema produtivo ou econômico está nas mãos de um aparelho automatizado, ou seja, um mecanismo institucionalizado controla os seres humanos em suas atividades cotidianas assim como os recursos naturais (Polanyi, 1968b, p. 62).

Emergiu, nesse sentido, uma "esfera econômica" que está perfeitamente delimitada das outras instituições da sociedade. Uma vez que nenhum agregado humano pode sobreviver sem um aparelho produtivo funcional, sua corporização (embodiment) em uma esfera distinta e separada produziu o efeito de tornar o resto da sociedade dependente dessa esfera (...) Como resultado, o mecanismo de mercado tornou-se num fator determinante para a vida do corpo social. Não admira que a agregação humana emergente corresponda a uma sociedade 'econômica' em um grau nunca antes visto (Polanyi, 1968b, p. 63).

Os "motivos econômicos" reinam, então, de um modo supremo em um mundo que lhes é familiar e o indivíduo é levado a agir de acordo com eles sob pena de ser esmagado pelo mercado reinante. Tal conversão forçada a uma visão utilitarista moldou de forma profunda a compreensão do homem ocidental acerca de si mesmo.

Em suma, se em todas as sociedades do passado, a economia encontravase incrustada (embedded) na sociedade, isto é, não constituía uma esfera autônoma, no presente, ao contrário, há uma sociedade inteira inserida no mecanismo de sua própria economia - uma sociedade de mercado ${ }^{7}$. A identificação logicamente falaciosa dos fenômenos econômicos com os de mercado tornou-se quase requisito prático com a emergência da nova sociedade e seu modo de vida nascido dos primórdios da Revolução Industrial, conforme Polanyi (1977a, p. 9). Nesse sentido, "o que designamos por falácia economicista foi e é um erro essencialmente do ponto de vista teórico. Isso porque, para todos os efeitos práticos, a economia consiste agora de fato em mercados e o mercado envolve de fato a sociedade" (Polanyi, 1977a, p. 9).

A relevância da visão "economicista", por conseguinte, prendeu-se com sua exata capacidade para dar origem a uma unidade de motivações e valorações que criaria na prática o que preconizou como ideal, nomeadamente a identidade do mercado e da sociedade. Explicitando-se:

A "mentalidade de mercado" continha (nada menos do que) a semente de toda uma cultura - com suas possibilidades e limitações - e a visão interior do homem e da sociedade induzidas pela vida em uma economia de mercado derivaram,

(7) Cf. Machado (2010) para uma análise mais detalhada do conceito de (des)incrustação da economia e da sua utilização na disciplina da (Nova) Sociologia Econômica.

174 Economia e Sociedade, Campinas, v. 21, n. 1 (44), p. 165-195, abr. 2012. 
necessariamente, da estrutura fundamental de uma comunidade humana organizada por meio do mercado (Polanyi, 1977a, p. 10).

Espera-se estar agora bem claro que a combinação dos dois significados de economia, em particular, o predomínio da definição formal foram originados por condições específicas e especiais: os últimos dois séculos produziram na Europa Ocidental e América do Norte uma organização singular da vida/sobrevivência do homem, sendo que tal forma de economia (economy) consiste em um sistema de mercados formadores de preços (price-making markets). Dado que os atos de troca envolvem os participantes em escolhas induzidas por uma insuficiência de meios, esse sistema foi reduzido a um padrão passível de ser objeto da aplicação dos métodos baseados no significado formal da economia. Em outras palavras, enquanto a economia for controlada pelo referido sistema de mercados formadores de preços, os significados formal e substantivo coincidem na prática. Assim, parece não haver razões válidas para distinguir entre dois sentidos de um termo destinados a coincidir na prática - isso, quando aplicados à nossa própria economia (de mercado), claro está (Polanyi, 1968a, p. 141; 1977a, p. 10-11).

Essa fusão em um único conceito, todavia, é prejudicial para uma metodologia precisa nas Ciências Sociais. O antropólogo, o sociólogo ou o historiador - ao estudarem o lugar ocupado pela economia nas sociedades humanas - são confrontados com uma grande variedade de instituições para além do(s) mercado(s), nas quais a subsistência (livelihood) do homem está incrustada. Sendo assim, os problemas não podem ser enfrentados com a ajuda de um método analítico desenvolvido para uma forma especial de economia, dependente da presença de elementos específicos de mercado (Polanyi, 1968a, p. 141).

\subsection{O paradigma formalista: racionalidade meios/fins e escassez}

Polanyi examina os conceitos formais a partir da maneira como a lógica da ação racional produz a ciência econômica formal e como esta, por sua vez, dá origem à análise econômica (economic analysis). A ação racional pode ser definida como a escolha de meios em relação aos fins a atingir, ou seja, refere-se à relação dos meios com os fins. Assumindo ser a escolha induzida por uma insuficiência dos meios, a lógica da ação racional transforma-se naquela variante da teoria da escolha em que Polanyi (1968a:142) designa por ciência econômica formal (formal economics) apoiada por Berthoud (1990, p. 175). Afirma o seguinte:

A ciência econômica formal reporta-se ao chamado postulado da escassez. Requer, em primeiro lugar, uma insuficiência dos meios e, em segundo, que a escolha seja induzida por essa insuficiência (...) Para que a insuficiência induza a escolha, é necessário que exista mais do que um uso para os meios, assim como uma 
hierarquização (grading) dos meios, isto é, ao menos dois meios ordenados em sequência preferencial (Polanyi, 1968a, p. 143).

Ora, tendo definido a escolha, insuficiência e escassez em termos operacionais, é fácil constatar, segundo Polanyi (1968a, p. 144), que tal como pode existir escolha de meios sem insuficiência, igualmente haverá insuficiência de meios sem escolha. A escolha, de acordo ainda com Polanyi (1977b, p. 25), poderá ser induzida por uma preferência do bem face ao mal - escolha moral - ou consistir em uma encruzilhada (por exemplo, dois caminhos que conduzem ao mesmo destino) - escolha operacional. De qualquer maneira, uma abundância de meios, longe de diminuir as dificuldades de escolha, ao contrário, aumenta-as. Ademais, a escassez poderá ou não estar presente nas diversas sociedades humanas. Com efeito, em algumas civilizações, as situações de escassez parecem ser uma situação quase excepcional, enquanto, em outras, parecem estar dolorosamente generalizadas (Polanyi, 1968a, p. 144).

Chega-se dessa forma à análise econômica, disciplina que resulta da aplicação da ciência econômica formal a uma economia de um determinado tipo um sistema de mercado. Aqui, a economia está corporizada em instituições que fazem as escolhas individuais originarem movimentos interdependentes os quais constituem o processo econômico, alcançado-se isso mediante uso generalizado de mercados formadores de preços, conforme Polanyi (1968a, p. 144). Assim, a introdução generalizada do poder de compra como meio de aquisição converte o processo de satisfação das necessidades em uma afetação de meio(s) insuficiente(s) com usos alternativos, nomeadamente, o dinheiro, segundo Polanyi (1977b, p. 28-29). Segue-se que tanto as condições de escolha como suas consequências são quantificáveis sob a forma de preços (Polanyi, 1968a, p. 144145).

Desse modo, hoje em dia, está perfeitamente instalada a crença universal de que não existe o suficiente de coisa alguma, por vezes assumindo a forma de uma proposição acerca da natureza limitada da oferta, em outras, a de um postulado acerca da natureza ilimitada das necessidades individuais, de acordo com Polanyi (1977b, p. 29). Em qualquer dos casos, trata-se de asserções dogmáticas que cobrem uma definição arbitrária e uma circunstância histórica específica:

Uma vez estando o ser humano circunscrito ao "indivíduo no mercado", as proposições são fáceis de substanciar. De seus desejos e necessidades, apenas interessam aqueles que o dinheiro pode satisfazer por meio da compra das coisas que são oferecidas nos mercados; os desejos e as necessidades são eles próprios restritos àqueles dos indivíduos isolados. Assim, por definição, desejos nem necessidades para além dos satisfeitos pelo mercado são reconhecidos e nenhuma 
pessoa que não o indivíduo em isolamento é aceito como ser humano ${ }^{8}$ (Polanyi, 1977b, p. 29).

No referido contexto, qualquer discussão acerca da natureza dos desejos e necessidades humanas, em geral, perde toda a sua substância pois, como é fácil constatar, o que está aqui a ser testado não é natureza das necessidades humanas, mas apenas a descrição de um quadro de mercado enquanto situação de escassez (Polanyi, 1977b, p. 29).

No que se refere ao homem, o paradigma racional/formal preconiza a visão de que seus motivos podem ser descritos como "materiais" ou "ideais" e os incentivos mediante os quais a vida cotidiana é organizada derivam necessariamente dos motivos materiais, em particular, da fome e (desejo de) ganho - os motivos "econômicos" por excelência (Polanyi, 1977a, p. 11; Berthoud, 1990, p. 174).

Esse mundo de "motivos econômicos", todavia, é baseado em uma falácia dado que, intrinsecamente, a fome e o ganho não são mais "econômicos" do que o amor ou o ódio, o orgulho ou o preconceito. Nenhum motivo humano é assim por si só. O que fez a sociedade, a partir do séc. XIX, encarar a fome e o ganho como "econômicos" foi, simplesmente, a organização da produção sob uma economia de mercado (Polanyi, 1968b, p. 63; Block; Somers, 1984, p. 63).

No âmbito do sistema, caso o homem pretenda sobreviver, é compelido a comprar bens no mercado com a ajuda de um rendimento derivado da venda de outros bens (ou de seu trabalho). Obviamente, o sistema funciona apenas se os indivíduos possuírem razões para se empregarem em atividade com vista à obtenção de um rendimento. Os motivos da fome e do ganho - separada e conjuntamente - providenciam-lhe tais razões. São dois motivos, então, acoplados à produção e, consequentemente, denominados "econômicos". A assunção de que a fome e o ganho são os incentivos nos quais se baseiam qualquer sistema econômico é completamente infundada, pois, analisando-se as mais variadas sociedades humanas, verifica-se que, por vezes, a fome e ganho não constituem incentivos à produção e, em outras, estão fundidos com novos motivos poderosos

(8) Na sequência do que foi apresentado nos últimos parágrafos, note-se que Schumpeter, por exemplo, considera positivo - e até desejável - este caráter ilimitado das necessidades humanas. Isso porque, caso se atingisse um estado de plena saciedade, o capitalismo - sendo um processo evolutivo - caminharia para um estado estacionário atrófico dado não haver motivos para continuar a desenvolver as capacidades produtivas. É pouco provável, pois, à medida que são alcançados padrões de vida mais elevados, as necessidades expandem-se automaticamente, emergindo ou sendo criadas novas necessidades - elas acabam por ser, quase por definição, insaciáveis. Assim, o permanente surgimento de novas necessidades e, por via destas, de novos produtos estimula as mudanças nas estruturas produtivas. Fica-se na presença da denominada heterogonia de objetivos, isto é, a contínua fixação de novos objetivos, obedecendo a uma lógica de conflito e competição (ágon) entre os vários indivíduos (hetero), possibilitando-se o funcionamento "saudável" da sociedade capitalista (cf. Schumpeter, 1992, p. 131; Graça, 1995, p. 27-28). 
(Polanyi, 1968b, p. 64-65; Berthoud, 1990, p. 174; Block; Somers, 1984, p. 6364). Isso pelo seguinte motivo:

Aristóteles tinha razão: o homem não é um ser econômico, mas sim, um ser social. Ele não procura salvaguardar seu interesse pessoal com a aquisição de bens materiais, ao contrário, procura assegurar o bem-estar social, um estatuto social e benefícios (assets) sociais. Ele valoriza as posses primariamente como um meio que lhe permite atingir esses fins. Seus incentivos possuem um carácter "combinado" com vista à tentativa de garantir a aprovação social - os esforços produtivos não são mais do que incidentais para tal. Isso porque a economia humana está, em regra, submersa nas relações sociais. A mudança para um tipo de sociedade, pelo contrário, submersa no sistema econômico é um desenvolvimento inteiramente novo (Polanyi, 1968b, p. 65).

No campo da antropologia, Malinowski e Thurnwald demonstraram que, no tocante ao homem primitivo, não há quaisquer evidências de um egoísmo cru, nem da pretensa propensão para a troca e a barganha. A posição dele na sociedade e o direito à parte dos recursos comuns estavam-lhe plenamente assegurados, não importando qual papel havia desempenhado na caça, no pastoreio etc. De fato, o indivíduo não se encontra ameaçado pela fome a não ser que a comunidade em seu todo também esteja em situação semelhante. Aplica-se o mesmo ao estímulo do ganho individual, sendo uma característica distintiva da economia primitiva a ausência de qualquer desejo de obter lucros da produção e troca, não funcionando o ganho como um impulso para trabalhar. Se esses chamados motivos "econômicos" fossem naturais no homem, teríamos de julgar todas as sociedades primitivas e antigas como sendo profundamente não naturais (Polanyi, 1968b, p. 65-66).

Daqui se deduzem os limites dentro dos quais a análise econômica prova ser um método eficaz. O uso do significado formal denota a economia como uma sequência de atos "economizadores", isto é, escolhas induzidas por situações de escassez. Ora, a aplicabilidade das citadas regras para definir uma economia depende de essa economia ser ou não de fato uma sequência de tais atos. Tem-se a seguinte reflexão:

A relação entre a ciência econômica formal e a economia humana é, com efeito, contingente. Fora do âmbito de um sistema de mercados formadores de preços, a análise econômica perde a maior parte de sua relevância enquanto método de investigação do funcionamento da economia (Polanyi, 1968a, p. 145).

A ênfase na análise formalista trouxe uma completa desconsideração pelos requerimentos de outras disciplinas como a sociologia das instituições econômicas, a ciência econômica primitiva ou a história econômica, que também se debruçam sobre o estudo da sobrevivência humana. Acabou por se produzir nos economistas uma concepção insistente, segundo a qual todas as disciplinas que 
lidam com a economia têm como verdadeiro objeto de estudo não algum aspecto da satisfação das necessidades materiais, mas, antes, as escolhas associadas ao uso de meios escassos ${ }^{9}$ (Polanyi, 1977b, p. 24).

$\mathrm{Na}$ ausência de mercados e preços de mercado, o economista não consegue fornecer uma ajuda para o estudo das economias primitivas; de fato, pode até dificultar essa tarefa. A pré-história, a história antiga e, aliás, toda a história com exceção dos últimos séculos, foram palco de economias cuja organização diferia de tudo o que é assumido por ele. A diferença poderá ser resumida em um único ponto - não possuíam qualquer sistema de mercados formadores de preços. Em todo o espectro de disciplinas econômicas, o ponto de interesse comum é definido pelo processo mediante o qual a satisfação das necessidades materiais é providenciada. Localizar esse processo e examinar seu funcionamento poderá apenas ser alcançado por meio da mudança da ênfase em um tipo de ação racional para uma configuração de movimentos de bens e pessoas que, efetivamente e na realidade, constituem, segundo Polanyi et al. (1968, p. 119), a economia (economy).

\subsection{Um novo ponto de partida metodológico: a economia substantiva ou a economia enquanto processo instituído}

A fonte da concepção substantiva é a economia empírica. Assim, "pode ser brevemente definida como o processo instituído de interação entre o homem e o seu ambiente, que resulta numa contínua oferta de meios materiais para satisfazer as suas necessidades" (Polanyi, 1968a, p. 145).

A economia é, pois, para Polanyi (1977b, p. 31), um processo instituído constituído por dois níveis: i) refere-se à interacção do homem com o ambiente natural e social que o rodeia; ii) refere-se à institucionalização desse processo. $\mathrm{Na}$ realidade, ambos são inseparáveis. Para fins de uma melhor exposição e compreensão dos mesmos, no entanto, Polanyi analisa-os separadamente.

"Processo" (de interação) sugere uma análise em termos de movimento. Os movimentos podem referir-se a mudanças na localização, apropriação ou em ambas. Em outras palavras, os elementos materiais podem alterar a posição quer mudando de lugar (movimentos locacionais), quer mudando de "mãos" (movimentos apropriativos). Os dois tipos de movimentos esgotam as

(9) Quer dizer que acabou por se assistir a um "triunfo" da definição herdada de Lionel Robbins (cf. 1945) ainda hoje, considerada a formulação clássica (Stanfield, 1986, p. 33), segundo a qual a "economia (economics) é a ciência que estuda o comportamento humano enquanto uma relação entre fins e meios escassos que possuem usos alternativos" de acordo com Robbins (1945, p. 16). Polanyi alertou para o fato de que se, por um lado, a definição de Robbins pode ser útil para a ciência econômica, por outro, distorce profundamente a questão no âmbito das Ciências Sociais e torna-se um conceito prejudicial (Polanyi, 1968a, p. 142). 
possibilidades contidas no processo econômico enquanto um fenômeno natural e social (Polanyi, 1968a, p. 146).

Em suma, nos movimentos locacionais, tudo se move espacialmente, incluindo-se a produção e o transporte. Em um movimento apropriado ou a(s) pessoa(s) que dispõe(m) das coisas, ou o grau de seus direitos de disposição sobre essas coisas mudam, sendo mais claramente ilustrado pelas transações e disposições (Polanyi, 1977b, p. 31-32; Carvalho, 2007, p. 133).

Em nível interativo, então, a economia compreende o homem enquanto coletor, cultivador, transportador e produtor de coisas úteis, assim como a natureza enquanto "agente" facilitador ou constrangedor compreende igualmente sua interpenetração em sequência de acontecimentos físicos, químicos, fisiológicos, psicológicos e sociais ocorrendo da menor para a maior escala. O processo é empírico, suas partes são passíveis de definição operacional e observação direta (Polanyi, 1977b, p. 33).

Não obstante, com vista a alcançar uma coerência manifesta da economia, o processo de interação deverá adquirir maior conjunto de propriedades, sem as quais a economia mal conseguiria existir.

Se a sobrevivência material do homem fosse o resultado de uma mera cadeia causal - não possuindo nem uma localização definida no tempo ou no espaço (isto é, unidade e estabilidade), nem pontos permanentes de referência (isto é, estrutura), nem modos definidos da ação relativamente ao todo (isto é, função), nem formas de ser influenciada pelos objetivos societais (isto é, relevância em termos de políticas) - nunca poderia ter alcançado a dignidade e importância da economia humana. As propriedades de unidade e estabilidade, estrutura e função, história e políticas conjugam-se (accrue) na economia por meio de seu revestimento institucional. Isso estabelece a base para o conceito de economia humana como processo institucionalizado de interação que funciona para providenciar os meios materiais à sociedade (Polanyi, 1977b, p. 34).

Em outras palavras,

Reduzida a uma interação mecânica, biológica e psicológica de elementos, esse processo econômico não possuiria uma realidade abrangente e compreensiva (allround). Não contém mais do que o esqueleto do processo de produção e de transporte, assim como das mudanças apropriativas. Na ausência de qualquer indicação sobre as condições societais das quais têm origem os motivos dos indivíduos, haveria pouco (ou nada) para sustentar a interdependência dos movimentos e sua recorrência, das quais depende a unidade e estabilidade do processo (Polanyi, 1968a, p. 147).

Daqui se retira a importância transcendente do aspecto institucional da economia. Em suma, para Polanyi, a instituição (instituting) do processo econômico reveste o referido processo com unidade e estabilidade, produz uma estrutura com determinada função na sociedade, muda o papel do processo na 
sociedade - adicionando um significado à sua história - e centra o interesse nos valores, motivos e políticas. Unidade e estabilidade, estrutura e função, história e políticas dispõem, portanto, operacionalmente o conteúdo da asserção de Polanyi segundo a qual a economia humana é um processo instituído (Polanyi, 1968a, p. 148; Carvalho, 2007, p. 135).

Como nota Stanfield, "a preocupação metodológica de Polanyi é agora clara. O reconhecimento do primado da sociedade na vida humana, que a atividade econômica é uma atividade social, requer um novo ponto de partida no que toca ao pensamento econômico" (1986, p. 47-48). A base de tal ponto de partida é também clara: "apenas o significado substantivo da economia é capaz de providenciar os conceitos que são requeridos pelas Ciências Sociais para uma investigação de todas as economias empíricas, passadas e do presente" (Polanyi, 1968a, p. 140).

Com efeito, se a abordagem da antropologia, história econômica e dos sistemas econômicos comparados não pretende estar fatalmente prefigurada, isto é, caso se queira tornar possível uma análise institucional fundamental, o quadro operativo deverá ser libertado de todos os pré-juízos e preconceitos formalistas. A comparação de sistemas econômicos poderá contribuir para resolver tanto problemas teóricos como de adoção de políticas na medida em que permite aos economistas alargar o campo de visão para além de sua limitada experiência institucional (de mercado) (Stanfield, 1986, p. 48-49; Humphreys, 1969, p. 196).

As bases institucionais e históricas alargadas da sobrevivência (livelihood) do homem, cujo estudo deverá constituir a principal tarefa teórica dos investigadores e acadêmicos são, para Polanyi, as bases de uma verdadeira teoria econômica universal. A teoria econômica deve possuir uma base empírica tão próxima de universal quanto possível. A conotação substantiva da economia é universal porque todos os agrupamentos humanos devem, de alguma forma, assegurar a sobrevivência, trabalhando as leis da natureza para seu proveito. A provisão é universal, mas o motivo de tal provisão ser eficiente ou maximizadora é uma questão de fatos empíricos. Para o substantivista tal como para o sociólogo econômico, a racionalidade econômica deverá ser considerada como um valor institucionalizado. Ademais, mesmo se estiver presenteem dada sociedade, a racionalidade econômica não existe em um vácuo mas, antes, está inserida na complexidade de valores que não podem ser assumidos como consistentes ou não competitivos entre si (Stanfield et al., 2004, p. 258-260; 1986, p. 49-50; 1980, p. 600).

A convicção de Polanyi acerca da necessidade de uma teoria econômica universal fundada sobre uma história também econômica universal é profundamente prática em sua inspiração. Ele estava convencido de que as respostas aos maiores problemas dos tempos modernos necessitariam nada menos 
que de tal perspectiva universal, ou melhor, se a sociedade democrática industrial quiser ter uma hipótese contra a magnitude e o número de problemas sociais que enfrenta, deverá abordá-los com uma panóplia de instrumentos tão alargada e variada quanto possível (Stanfield et al., 2004, p. 260; 1986, p. 50).

A crítica metodológica do formalismo por parte de Polanyi é também igualmente bastante prática em suas motivações. Seu objetivo fundamental procede diretamente daconvicção de que, apenas por meio de uma reconsideração (profunda) do passado, poderá um novo entendimento do presente emergir mediante o qual a criação de um futuro desejável será conduzida (Standfield, 1986, p. 52).

Eis o problema, porém, que se coloca:

A mudança nas Ciências Naturais de um quadro concetual para outro é completamente diferente do que fazer o mesmo nas Ciências Sociais. É como tentar reconstruir uma casa, as fundações, paredes e tudo mais, enquanto se continua a viver lá dentro. Necessita-se livrar da noção dominante segundo a qual a economia (economy) é um campo de experiência de que os seres humanos sempre estiveram conscientes. Empregando uma metáfora, os fatos da economia estavam originalmente incrustados em situações que não eram de natureza econômica, não sendo os meios nem os fins primariamente materiais. A cristalização do conceito de economia foi uma questão de tempo e história, mas nem o tempo nem a história providenciaram ao homem aqueles instrumentos concetuais requeridos para penetrar na malha das relações sociais na qual a economia está incrustada. Essa é a tarefa (...) da análise institucional (Polanyi et al., 1968, p. 118-119).

Conclui-se que a economia humana está incrustada (embedded) e imiscuída (enmeshed) nas instituições econômicas e não econômicas. Nesse sentido, a inclusão do não econômico é vital, porque a religião ou o governo podem ser tão importantes para a estrutura e o funcionamento de uma economia como as instituições monetárias ou a disponibilidade de instrumentos e máquinas para aliviar o esforço dos indivíduos no trabalho. Assim, "o estudo da mudança do lugar ocupado pela economia na sociedade é (...) nada mais do que o estudo da maneira como o processo econômico está instituído em diferentes épocas e locais" (Polanyi, 1968a, p. 148).

\section{Breves apontamentos sobre a "escola Polanyiana" na antropologia econômica}

\subsection{Harry Pearson e o problema do excedente econômico}

Uma das obras substantivistas mais importantes - senão mesmo a mais importante - foi Trade and Market in the Early Empires, editada por Karl Polanyi, Harry Pearson e Conrad Arensberg (1957). Trata-se de uma coletânea de conteúdo riquíssimo, destacando-se - além de sua investigação histórica e empírica - um 
conjunto de artigos de cariz teórico e metodológico que desenvolvem a perspectiva institucionalista na base do que é proposto por Polanyi. Pense-se nomeadamente nas contribuições de Conrad Arensberg (cf. 1957) e Daniel Fusfeld (cf. 1957) no campo da antropologia, nas possibilidades de uma sociologia substantivista exploradas por Terence Hopkins (cf. 1957) ou no excurso de Walter Neale (cf. 1957) sobre o conceito de mercado ${ }^{10}$. Já se tratou alguns desses autores em outro momento (cf. Machado, 2009, p. 37-49) e, por questões de brevidade, será salientada somente a discussão de Harry Pearson em torno do conceito de excedente econômico e que constitui, de certa forma, um complemento à análise do conceito de escassez desenvolvida por Polanyi.

A contribuição mais inovadora de Pearson foi, talvez, sua análise crítica de um conceito até então quase consensual. Se não existe teoria alguma do desenvolvimento das instituições econômicas que tenha atingido uma generalidade próxima da teoria formal, há, apesar de tudo, um conceito largamente utilizado na antropologia e história que possui uma relação com a análise do desenvolvimento econômico similar à que se estabelece entre o postulado da escassez e a análise econômica. Este corresponde ao conceito de excedente (surplus), empregado de maneira que torna o surgimento de um " "excedente" acima do nível mínimo das necessidades de subsistência no determinante crítico da evolução das instituições sociais e econômicas complexas desde o início. Então, a existência excedente dos meios é tida como a responsável pelo desenvolvimento das instituições econômicas e a insuficiência dos meios, como responsável por reforçar uma gestão utilitarista dos recursos, o que corresponde à economia no sentido formal (Pearson, 1957b, p. 320-321).

O argumento de Pearson é que, ao se empregar o conceito de excedente dessa maneira, representa-se uma abstração inadmissível das condições sociais que rodeiam a atividade diária de assegurar os meios materiais requeridos para a satisfação das necessidades. Assim como o conceito de escassez, o teorema do excedente é útil apenas quando as condições de um excedente específico são institucionalmente definidas. Tal como o postulado da escassez, o conceito de um excedente geral deriva-se daquele complexo ideal e institucional que encara o homem como um átomo economizador com uma propensão para a troca e o

(10) Outro dos nomes que se destacou no campo da antropologia econômica substantivista foi Paul Bohannan. O autor dedicou grande parte de seu trabalho ao estudo da economia dos Tiv (cf. Bohannan, 1955; 1959), um grupo étnico que vive na África Ocidental (particularmente na Nigéria e nos Camarões). Escreveu ainda a obra Social Anthropology (Nova Iorque: Holt, Rinehart and Winston, 1963) e editou igualmente, junto a George Dalton, uma das obras substantivistas mais importantes: Markets in Africa (Evanston: Northwestern University, 1962). Merece ainda referência Marshall Sahlins. Embora não se trate do substantivista mais "puro" (cf. Orlove, 1986, p. 86-87), é inegável a influência que recebeu de Karl Polanyi, nomeadamente no que se refere à utilização das formas de integração - reciprocidade, redistribuição e troca (mercado) - como instrumento de análise (cf. Sahlins, 2004). Cf. Machado (2009, p. 93-100) para uma exposição das suas contribuições nesse âmbito. 
regateio e providencia o sistema de mercados para tornar isso possível. Já foi dito que, sob um sistema de mercado, o processo econômico é organizado por meio de situações de escassez. Poderá ser acrescentado que, por necessidade (intrínseca), o comportamento do mercado é direcionado no sentido da criação de excedentes. Comete-se um erro, no entanto, quando se assume que as características institucionais de uma economia de mercado são um aspecto natural da vida econômica (Pearson, 1957b, p. 321).

Parcelas maiores ou menores da população de todas as sociedades vivem em um nível de subsistência considerado inadequado pela ciência. As pessoas não despendem, contudo, de todo o seu tempo disponível a produzir comida. Quer nas sociedades primitivas, quer nas contemporâneas, mesmo os indivíduos mais pobres usam seus poucos recursos de formas não utilitárias (dançam, cantam, lutam etc.) Assim, aquilo que parece ser um fato objectivo da natureza, desintegrase após uma examinação mais aprofundada. A verdade é que "o homem não vive apenas do pão", não interessa quão escasso este seja. Na base do teorema do excedente, está assumida uma primazia do comer, sobre o pensar, socializar, governar, construir, trocar, jogar etc. Isso, porém, configura um cru determinismo econômico que baseia o desenvolvimento social e econômico nas capacidades estreitas do estômago humano (Pearson, 1957b, p. 324-325).

É preciso citar que a economia, em todos os seus níveis de existência material, é um processo social de interação entre o homem e seu ambiente no decurso do qual bens e serviços modificam a forma, são movidos e mudam de mãos. Eles são produzidos e distribuídos. A forma desse processo, isto é, sua forma institucional e os motivos que o colocam em movimento não são determinados por qualquer fator individual, natural ou humano, mas apresentam o resultado de vários níveis interdependentes da existência humana: ecológicos, tecnológicos, sociais e culturais. As questões relativas a que coisas e em que quantidade uma determinada sociedade produz, quem é responsável pela produção, quanto é consumido e em que proporção pelos vários grupos sociais e quanto é poupado ou desviado do consumo imediato e para que fins, são resolvidas apenas por meio da interação complexa dessas variáveis. O homem, ao viver em sociedade, não produz um excedente a não ser que o designe como tal e, então, seu efeito é dado pela forma como está institucionalizado (Pearson, 1957b, p. 326).

Conclui-se que a inter-relação entre os aspectos materiais e sociais da existência (humana) é de tal ordem que eles não podem ser separados em sequências do tipo "primeiros e segundos", "antes e depois". O sistema de mercado, com sua separação institucional do econômico e social, é apenas uma exceção aparente. Aqui, também, aqueles excedentes que parecem surgir do nada são explicados apenas pelas características institucionais da economia de mercado. Da mesma forma, não será útil admitir que o excedente seja uma condição necessária, mas não suficiente da mudança, pois isso é falhar a questão chave. Existem sempre e em todos os lugares potenciais excedentes disponíveis. São, na 
verdade, os meios institucionais que os tornem possíveis. Esses meios, para aumentar o esforço, colocar de parte a quantidade extra e criar um excedente, são tão variados como a própria organização do processo econômico (Pearson, 1957b, p. 338-339).

\subsection{George Dalton: o "herdeiro" de Polanyi}

Dalton é considerado quase, consensualmente, o autor "polanyiano" por excelência no campo da antropologia econômica. Aliás, como nota Arensberg, "Dalton é o sucessor lógico de Polanyi e o seu trabalho representa o culminar do ímpeto de Polanyi em direção ao renascimento da economia (economics) histórica institucional e ao uso teórico apropriado dos dados etnográficos e históricos na ciência econômica e na antropologia" (citado em Dalton, 1969, p. 80). seguinte:

Com efeito, Dalton está em perfeita sintonia com Polanyi quando afirma o

Todas as sociedades devem possuir algum tipo de organização econômica (...) arranjos (institucionais) estruturados para providenciar bens e serviços materiais mas se esses arranjos se assemelham ou não às regras economizadoras da troca mercantil é uma questão de investigação empírica (Dalton, 1968a, p. xxxii).

\section{Acrescenta ainda a reflexão:}

Caso se pretenda investigar, de modo sistemático, o grande número de economias pré-industriais estudadas por antropólogos e historiadores, é necessário abordagem conceitual que não comprometa a visão segundo a qual o que for descoberto será entendido meramente como variante do próprio sistema de mercado (Dalton, 1968a, p. xxxiii).

George Dalton dedicou uma parte considerável de seus estudos às questões teóricas no campo da antropologia econômica ${ }^{11}$ (cf. 1961; 1967; 1968a; $1968 b ; 1969 ; 1990)$. Dessa forma, segue a linha de raciocínio preconizada por Polanyi ao considerar que a palavra "economia" possui dois significados distintos e independentes. No sentido substantivo, economia refere-se à provisão de bens materiais que satisfazem necessidades biológicas e sociais. $O$ significado substantivo é perfeitamente geral em sua aplicabilidade porque todas as comunidades, independentemente das diferenças em seu ambiente natural, técnicas de produção ou traços culturais, são compostas por seres humanos cuja existência biossocial depende da provisão sustentada de itens materiais (Dalton, 1961, p. 5-6; Elardo, 2003, p. 42).

(11) É ainda de realçar a influência notória de Polanyi sobre as contribuições de Dalton para outras matérias, nomeadamente, no que se refere à utilização das formas de integração - reciprocidade, redistribuição e mercado - em análises empíricas (cf. 1962) e ao estudo que fez sobre o "dinheiro primitivo" (cf. 1965). Para uma análise mais detalhada das mesmas, cf. Machado (2009, p. 73, 89-93). 
O segundo significado de economia poderá ser descrito em termos "economizadores". Denota um conjunto especial de regras desenhadas para maximizar os resultados de algum objetivo ou para minimizar o gasto de alguns meios. Assim, não possui necessariamente uma conexão com o significado substantivo da economia, pois seria prejudicial assumir que a provisão organizacional dos bens materiais deverá ser universalmente alcançada por meio de um cálculo economizador (Dalton, 1961, p. 6-7; Elardo, 2003, p. 42).

Consequentemente, observa-se o seguinte:

Um bom quadro teórico para a antropologia econômica deve ser (bastante) claro acerca das similaridades e diferenças entre a nossa própria economia e as economias primitivas e agrícolas ${ }^{12}$ (peasant economies), acerca da relevância da ciência econômica convencional para a antropologia econômica e deve conter uma formulação explícita das matérias a serem analisadas (Dalton, 1969, p. 69)

Então, como já visto em Polanyi, a antropologia econômica é melhor conduzida no âmbito de um quadro de sistemas econômicos comparados que considere todas as economias - pré-industriais, desenvolvidas e em vias de desenvolvimento - de que há registros. Essa análise encontra-se, hoje em dia, dispersa por vários ramos da Ciência Econômica, História, Sociologia e Antropologia, cada um deles contribuindo com informação útil para o largo espectro de tópicos estudados pela Antropologia Econômica (Dalton, 1969, p. 6970).

Qualquer que seja o agrupamento humano, fica-se na presença de pessoas com reconhecidas afinidades sociais e culturais - parentesco, religião, língua, vizinhança - expressas em algum tipo da comunidade partilhada ou de vida social. Isso significa que dois tipos de bens e serviços devem ser providenciados à comunidade: comida e outros requisitos materiais para a existência física e bens e serviços para a religião, defesa, resolução de disputas, ritos de passagem e outros aspectos da vida social e comunitária. A aquisição ou produção dos itens materiais e dos serviços ${ }^{13}$ necessários para a existência física e social nunca são deixadas ao acaso porque nem os indivíduos nem as comunidades poderiam sobreviver sem os mesmos. Por tal razão, é útil entender todas as comunidades ou sociedades como possuindo sistemas econômicos. A palavra "sistema" refere-se aos arranjos (arrangements) e regras estruturados que asseguram serem os bens materiais e os serviços providenciados de um modo repetido ao longo do tempo. Uma das tarefas

(12) Dalton entende por economias agrícolas (peasant economies) aquelas em que as transações comerciais (de mercado) no âmbito dos recursos e produção são quantitativamente importantes e o dinheiro, os preços (monetários) e o trabalho assalariado, habituais. Essas eram comuns especialmente na América Latina e Ásia antes e durante grande parte da época colonial (Dalton, 1968b, p. 182).

(13) No contexto das economias primitivas e agrícolas (peasant), Dalton usa o termo "serviços" para referir-se aos serviços providenciados por artesãos, tais como ferreiros, carpinteiros etc. e aos serviços providenciados por pessoas que desempenham papeis políticos, religiosos e rituais (Dalton, 1969, p. 70)

186 Economia e Sociedade, Campinas, v. 21, n. 1 (44), p. 165-195, abr. 2012. 
da antropologia econômica consiste em identificar essas regras e arranjos sistemáticos nas várias sociedades (Dalton, 1969, p. 70; Elardo, 2003, p. 47-49).

Uma segunda semelhança entre as diversas economias é que todas utilizam algum(ns) tipo(s) de recursos naturais (terra, minerais etc.), cooperação humana (divisão do trabalho) e tecnologia (instrumentos e conhecimento da produção ou dos processos aquisitivos). Cada um desses elementos está estruturado, isto é, requer regras sociais - direitos e obrigações específicos. Chama-se de organização econômica um conjunto de regras instituídas mediante as quais os recursos naturais, a cooperação humana e a tecnologia são combinadas concomitantemente para que sejam providenciados os itens materiais e serviços de uma forma sustentada e repetida (Dalton, 1969, p. 70-72).

Nota-se, mais uma vez, presença da definição substantiva da economia, com a seguinte conclusão:

Em suma, todas as sociedades de que há registo possuem arranjos estruturados que providenciam os meios materiais (necessários) para a vida individual e comunitária. Chamam-se essas regras estruturadas de sistema econômico. A antropologia econômica delineia regras sociais da economia ao descrever as atividades e as visões e ao analisar os processos transaccionais e as relações nas comunidades préindustriais do mundo subdesenvolvido. Faz comparações entre as economias primitivas, agrícolas e as economias industriais desenvolvidas. Compara igualmente os componentes e os setores de uma economia: a afetação da terra e do trabalho, a organização do trabalho, a disposição da produção e a organização e a utilização das diferentes formas de dinheiro, mercados e comércio externo. Existem, contudo, diferenças muito importantes entre as diversas economias, diferenças em sua estrutura e performance, pelo que constituirá uma análise bastante valiosa (salientálas e) contrastá-las (Dalton, 1969, p. 72).

\section{O paradigma formalista}

Segundo as asserções do campo formalista, o comportamento maximizador é universal: "Um indivíduo maximiza alguma coisa, ou diferentes coisas em diferentes períodos - presumivelmente coisas que valoriza. [Logo,] a teoria geral da maximização pode ser aplicada em qualquer caso" (Leclair; Schneider, 1968, p. 8).

Seguindo esse raciocínio, para Burling (1968), a ciência econômica consiste no estudo da afetação de recursos escassos a fins alternativos: "Acredito que eles [Polanyi e os seus associados] estão errados (...) e sinto que as suas discussões obscurecem a possibilidade de os [povos] primitivos também poderem "economizar" (i.e., praticar cálculos racionais), mesmo na ausência de um mercado" (Burling, 1968, p. 170). 
Indivíduos, em todas as sociedades, escolhem o que fazer de modo a maximizar quaisquer que sejam os seus fins. Assim, existem meios disponíveis para alcançar esses fins escassos. O indivíduo, portanto, tem de escolher os meios de acordo com suas limitações de uma forma que maximize os resultados. Então, o "problema econômico" consiste em analisar o contexto de uma "maximização constrangida" (constrained maximization) (Elardo, 2003, p. 52; del Toro, 1999, p. 92).

\section{Aliás,}

Não se pode argumentar que a 'economização', o cálculo cuidadoso das escolhas com vista ao alcance de determinados objetivos, não existe simplesmente porque $o$ quadro institucional particular que ajuda a efetuar escolhas economizadoras (o mercado) está ausente. Os indivíduos primitivos não são presumivelmente mais nem menos racionais do que qualquer dos homens de hoje, embora possam utilizar diferentes instituições para expressar a sua racionalidade (BURLING, 1968, p. 178).

Em suma, a opinião de Burling é que a racionalidade, tal como entendida pela ciência econômica neoclássica, é geral e as instituições, específicas, pois a existência da racionalidade não depende de quaisquer instituições, nomeadamente do mercado. Apresenta-se, portanto, o seguinte:

Dizer que um indivíduo procura maximizar suas satisfações é postular pouco mais do que um truísmo (...) Mas a ideia da maximização não pode ser abandonada uma vez que qualquer discussão acerca do comportamento orientado para (determinados) objetivos, ou qualquer análise da escolha, implica na teoria da maximização. Igualmente, pode-se explicitar uma noção comum nas Ciências Sociais e, nesse sentido, para todo o pensamento cotidiano (...) Sob tal ponto de vista, economiza-se em tudo o que se faz. Há sempre a tentativa de maximizar as satisfações de alguma forma, portanto as pessoas são remetidas para a noção de que a Ciência Econômica lida não com um tipo, mas com um aspecto do comportamento (humano) (Burling, 1968, p. 183-184).

Edward LeClair Jr. é, provavelmente, o formalista mais conhecido (cf. Elardo, 2003). Existem dois argumentos principais que o autor recupera de outros formalistas, nomeadamente, de Burling: i) todo o comportamento econômico consiste em um maximizador; ii) o modelo substantivista está errado, pois centrase exclusivamente nos bens (e serviços) materiais, conforme Elardo, (2003, p. 56). Tendo abordado o primeiro, debruça-se um pouco sobre o segundo. Como nota LeClair (1968, p. 190):

Os economistas já não acreditam (atualmente), se é que alguma vez acreditaram, que as necessidades humanas estão confinadas, nas sociedades de mercado, às necessidades materiais, nem assumem que isso é verdade em qualquer (outra) 
sociedade. Nenhuma assunção acerca da natureza materialista das necessidades humanas constitui um elemento necessário na teoria econômica contemporânea.

Tal como os primeiros formalistas, LeClair defende que, enquanto a definição substantiva de "economia" concentra-se na satisfação das necessidades materiais dos seres humanos, a definição formal refere-se à maximização da satisfação independentemente daquilo que contribui para isso ${ }^{14}$. Daqui, conclui-se que a definição formal é mais geral do que a substantiva, pois é aplicável sempre que a maximização da satisfação constituir o cerne do comportamento das pessoas (Elardo, 2003, p. 58).

Para o autor, não existe mais do que um conceito de economia, mas apenas o que se manifesta de modo peculiar em estruturas sociais e culturais diferentes. LeClair defende que é errado fazer distinção entre definição substantiva e definição formal de economia. Distinguir entre os dois significados implica em que ambas as definições sejam razoáveis, o que parece desnecessário se uma delas - a formal - é por natureza universal (Elardo, 2003, p. 57 e 59).

Acresce que o comportamento econômico maximizador refere-se necessariamente a bens escassos. Os substantivistas não foram bem-sucedidos demonstrando que a escassez não se aplica às economias primitivas, ao contrário, LeClair desenvolveu um quadro racional que postula a existência dessa escassez em todas as sociedades:

Pode-se reformular o postulado acerca da universalidade da escassez nos seguintes termos: os homens, em todo o lado (e em todas as épocas), estão confrontados com o fato de que as aspirações excedem suas capacidades. Sendo esse o caso, devem economizar capacidades para cumprirem as aspirações no maior grau possível (LeClair, 1968, p. 195).

Para concluir, refira-se que Cancian (cf. 1968) representa, talvez, a perspectiva mais "moderada" no contexto da posição formalista. O autor argumenta que ambos os lados do debate efetuaram formulações corretas, complementando, assim, a perspectiva formalista com alguns elementos da perspectiva substantivista/institucionalista. O caminho, a seguir, pela antropologia econômica deverá ser uma espécie de "meio-termo", isto é, um quadro teórico baseado no princípio formalista da universalidade da maximização, combinado com um reconhecimento da necessidade de incorporar as especificidades institucionais para “operacionalizar” esse princípio básico (Elardo, 2003, p. 68).

(14) Como já mencionamos a certa altura, na seção 3.2, Polanyi procura resolver uma ambiguidade semântica - que nos parece ser evidente no caso das críticas formalistas - ao afirmar que os bens e não as necessidades, são materiais, caso contrário, restringir-se-ia absurdamente a esfera da economia (cf. Polanyi, 1977b, p. 20). 
Em suma, enquanto a maior parte dos formalistas acreditam ser a teoria formal "subinstitucional", ou seja, que não tenham de responder a considerações institucionais, Cancian reconhece a necessidade de incorporar as instituições apropriadas nas teorias e modelos, particularmente, nos referentes às sociedades primitivas (Elardo, 2003, p. 70).

\section{Breve nota final}

Atente-se no Quadro 1 para uma síntese das perspectivas substantivista e formalista:

Quadro 1

Abordagens formalista e substantivista

\begin{tabular}{|l|c|c|}
\hline \multirow{2}{*}{ Base } & $\begin{array}{c}\text { Abordagem Formalista } \\
\text { (Teoria Neoclássica) }\end{array}$ & $\begin{array}{c}\text { Abordagem Substantivista } \\
\text { (Análise Institucional) }\end{array}$ \\
\cline { 2 - 3 } & Escassez Axiomática & $\begin{array}{c}\text { Necessidade Material } \\
\text { Axiomática }\end{array}$ \\
\hline Unidade de Análise & Individual & Sociedade \\
\hline $\begin{array}{l}\text { Objectivo Econômico } \\
\text { Assumido }\end{array}$ & Eficiência & Suficiência \\
\hline $\begin{array}{l}\text { Institucionalização do } \\
\text { Comportamento Econômico }\end{array}$ & $\begin{array}{c}\text { Implícita: } \\
\text { Homem Econômico }\end{array}$ & $\begin{array}{c}\text { Explícita: } \\
\text { Lugar Ocupado pela Economia }\end{array}$ \\
\hline
\end{tabular}

Fonte: Adaptado de Stanfield et al. (2006, p. 247).

Desse modo, a abordagem formalista parte de uma escassez ontológica e tem como objeto de análise o indivíduo ("racional") isolado que procura maximizar seus ganhos, isto é, cinge-se aos predicados do homo economicus. Por seu turno, a abordagem substantivista versa sobre as formas institucionais que o processo de satisfação das necessidades humanas reveste nas diferentes comunidades, procurando estudar o lugar ocupado pela economia na sociedade. Sua preocupação é a suficiência ao invés da eficiência.

Será suficiente recordar que a definição substantiva encara a economia como um processo instituído de interação entre o homem e o ambiente que o rodeia, o qual resulta em uma oferta contínua de meios materiais para satisfazer suas necessidades. Esse significado possui um caráter universal e constitui a base para o método preconizado por Polanyi: a análise institucional. Ora, a economia pode estar instituída de diferentes formas nas mais variadas sociedades, sendo que Polanyi identifica três padrões fundamentais designados por formas de integração - reciprocidade, redistribuição e troca (mercantil) - mediante a combinação das quais a economia adquire unidade e estabilidade, ou seja, a interdependência e a 
recorrência de suas partes ${ }^{15}$. Esta última - o mercado - desempenhou um papel largamente marginal nas sociedades humanas até o século XIX, quando ocorreu uma mudança para um tipo inteiramente novo de economia integrado pelos mercados formadores de preços. É precisamente sobre a história da ascensão da economia capitalista de mercado que versa a magnum opus de Karl Polanyi - $A$ Grande Transformação - expondo em pormenor o denominado processo de desincrustação (disembeddedness) da economia moderna ${ }^{16}$.

A concepção substantiva de economia e sua codificação na análise institucional constituem a pedra basilar de todo o edifício teórico construído por Polanyi. Isso lhe permite sustentar a "desontologização" da economia capitalista de mercado e refutar as noções de um "homem econômico", da racionalidade econômica, escassez, pretensa propensão para a troca e intercâmbio, de um individualismo e egoísmo inerentes à "natureza" humana, da procura inata do ganho etc. Em suma, todas as assunções da moderna teoria econômica baseiam-se em características presentes única e exclusivamente na economia de mercado. Nas sociedades do passado, a economia não estava separada da sociedade, não sendo muitas das vezes sequer identificável. Os princípios de organização social e padrões institucionais que regiam essas comunidades assentes na reciprocidade e redistribuição eram quase uma antítese do que sucede atualmente. Daqui, decorre a inadequação da teoria formalista para o estudo dessas mesmas sociedades.

Então, uma das principais lições a retirar do estudo do pensamento polanyiano é que não se deve projetar, automática e acriticamente, as características e especificidades da uma sociedade em outras. Não se deve assumir que a história foi uma espécie de odisseia em direção ao capitalismo, não sendo as comunidades do passado mais do que meros embriões - versões primitivas e subdesenvolvidas - da presente sociedade. A tentativa de formalizar uma ciência econômica comparada, genericamente relevante, deriva dessa exata necessidade

(15) Cf. Machado (2009, p. 54-68, p. 79-89) para uma análise das formas de integração propostas por Polanyi, assim como de sua aplicação empírica na obra Dahomey and the Slave Trade. De um modo sucinto, a reciprocidade denota movimentos entre pontos correlativos de grupos simétricos; pressupõe, por conseguinte, como pano de fundo institucional (background) a existência de simetria. Trata-se de um sistema de dádivas e contradádivas, um tomar e dar sucessivos (ex.: circuito Kula de Malinowski). A redistribuição designa movimentos apropriativos em direção a um centro e, também, no sentido inverso (do centro para "fora"); em termos institucionais, está dependente da presença de algum grau de centralidade (centricity) no grupo (ex.: impérios antigos: egípcio, romano etc. Daomé). A troca refere-se aos movimentos "vice-versa" que ocorrem entre os "agentes" sob um sistema de mercado; de modo a produzir integração, requer, portanto, um sistema de mercados formadores de preços. A troca mercantil (exchange) consiste, pois, em um movimento bidireccionado (two-way) de bens entre pessoas, orientado ao ganho resultante da mesma para os participantes. Nas sociedades primitivas ou tribais, opera a reciprocidade e, também, em parte, a redistribuição. As sociedades arcaicas são predominantemente redistributivas, embora possa haver espaço para alguma troca. Apenas nas sociedades modernas é que o sistema de mercados autorregulados assume-se como forma de integração dominante.

(16) Cf. Machado (2009, p. 102-145) para uma análise detalhada desta obra.

Economia e Sociedade, Campinas, v. 21, n. 1 (44), p. 165-195, abr. 2012. 
sentida pelo autor de salientar, com ênfase, as semelhanças e, talvez ainda mais importante, as diferenças entre os vários sistemas sociais e econômicos.

\section{Referências bibliográficas}

ARENSBERG, Conrad. Anthropology as history. In: POLANYI, Karl; ARENSBERG, Conrad; PEARSON, Harry (Ed.). Trade and market in the early empires. Chicago: Henry Regnery, 1957. p. 97-113.

BERTHOUD, Gérald. Toward a comparative approach: the contribution of Karl Polanyi. In: POLANYI-LEVITT, Kari (Ed.). The life and work of Karl Polanyi. Montréal: Black Rose Books, 1990. p. 171-182.

BLOCK, Fred; SOMERS, Margareth. Beyond the economistic fallacy: the holistic social science of Karl Polanyi. In: SKOCPOL, Theda (Ed.). Vision and method in historical sociology. Cambridge: Cambridge University Press, 1984. p. 47-84.

BOHANNAN, Paul. Some principles of exchange and investment among the Tiv. American Anthropologist, v. 57, n. 1, p. 60-70, 1955.

- The impact of money on an African subsistence economy. The Journal of Economic History, v. 19, n. 4, p. 491-503, 1959.

BURLING, Robbins. Maximization theories and the study of economic anthropology. In: LeCLAIR JR., E.; SCHNEIDER, H. K. (Ed.). Economic anthropology: readings in theory and analysis. New York: Holt, Rinehart and Winston Inc., 1968. p. 168-187.

CANCIAN, Frank. Maximization as a norm, strategy and theory. In: LeCLAIR JR., E.; SCHNEIDER, H. K. (Ed.). Economic anthropology: readings in theory and analysis. New York: Holt, Rinehart and Winston Inc., 1968. p. 228-233.

CARVALHO, Alexandre Galvão. Historiografia e paradigmas: a tradição primitivistasubstantivista e a Grécia Antiga. 2007. Tese (Doutoramento)-Instituto de Ciências Humanas e Filosofia, Universidade Federal Fluminense, 2007.

COOK, Scott. The obsolete "anti-market" mentality: a critique of the substantive approach to economic anthropology. American Anthropologist, New Series, v. 68, n. 2, p. 323-345, 1966.

. The "anti-market" mentality re-examined: a further critique of the substantive approach to economic anthropology. Southwestern Journal of Anthropology, v. 25, n. 4, p. $378-406,1969$.

DALTON, George. Economic theory and primitive society. American Anthropologist, v. 63, n. 1, p. 1-25, 1961.

- Traditional production in primitive African economies. The Quarterly Journal of Economics, v. 76, n. 3, p. 360-378, 1962.

. Primitive money. American Anthropologist, v. 67, n. 1, p. 44-65, 1965.

192 Economia e Sociedade, Campinas, v. 21 , n. 1 (44), p. 165-195, abr. 2012. 
DALTON, George. Tribal and peasant economies: readings in economic anthropology. New York: The Natural History Press, 1967.

Introduction. In: DALTON, George (Ed.). Primitive, archaic and modern economies: essays of Karl Polanyi. Boston: Beacon Press, 1968a. p. ix-liv.

Economics, economic development, and economic anthropology. Journal of Economic Issues, v. 2, n. 2, p. 173-186, 1968 b.

. Theoretical issues in economic anthropology. Current Anthropology, v. 10, n. 1, p. 63-102, 1969.

. Writings that clarify theoretical disputes over Karl Polanyi's work. In: POLANYI-LEVITT, Kari (Ed.). The life and work of Karl Polanyi. Montréal: Black Rose Books, 1990. p. 161-170.

Del TORO, Ramón Valdés. Notas de clase de antropologia de las instituciones econômicas: curso 1999-2000 (Universitat Autônoma de Barcelona). 1999. Disponível em: http://\%3cseneca.uab.es/antropologia/rvaldes/public archivos/rvaldesae.pdf. Acesso em: 5 nov. 2008.

DOWLING, John H. The goodfellows vs. the Dalton gang: the assumptions of economic anthropology. Journal of Anthropological Research, v. 35, n. 3, p. 292-308, 1979.

EDEL, Matthew. Economic analysis in an anthropological setting: some methodological considerations. American Anthropologist, New Series, v. 71, n. 3, p. 421-433, 1969.

ELARDO, Justin A. Reformulating the debate between the substantivists and formalists in economic anthropology: is the neoclassical model suitable for describing conditions in non-market economies? Tese (Doutoramento)- University of Utah, Utah, 2003.

. Economic anthropology and the evolution of institutionalist thought since the great debate. Paper presented at the AFIT (Association for Institutional Thought), Conference in Calgary, Canada, 2007a.

- Marx, marxists and economic anthropology. Review of Radical Political Economics, v. 39, n. 3, p. 416-422, 2007 b.

; CAMPBELL, Al. Choice and the substantivist/formalist debate: a formal presentation of three substantivist criticisms. Research in Economic Anthropology, v. 25, p. 267-284, 2006.

FIRTH, Raymond. The social framework of economic organization. In: LeCLAIR JR., E.; SCHNEIDER, H. K. (Ed.). Economic anthropology: readings in theory and analysis. New York: Holt, Rinehart and Winston Inc., 1968. p. 65-88.

FUSFELD, Daniel. Economic theory misplaced: livelihood in primitive society. In: POLANYI, Karl; ARENSBERG, Conrad; PEARSON, Harry (Ed.). Trade and market in the early empires. Chicago: Henry Regnery, 1957. p. 342-356.

GRAÇA, João Carlos. Werner Sombart e o homem econômico moderno. SOCIUS Working Papers, n. 3, 1995. 
HART, Keith, HANN, Chris. A short history of economic anthropology. Paper written for a workshop, 'Anthropological Approaches to the Economy', held at the Max Planck Institute for Social Anthropology, Halle, 21-24 Jun. 2006.

HEILBRONER, Robert. Modern economics as a chapter in the history of economic thought. History of Political Economy, v. 11, n. 2, p. 192-198, 1979.

HOPKINS, Terence. Sociology and the substantive view of the economy. In: POLANYI, Karl; ARENSBERG, Conrad; PEARSON, Harry (Ed.). Trade and market in the early empires. Chicago: Henry Regnery, 1957. p. 270-306.

HUMPHREYS, S. C. History, economics, and anthropology: the work of Karl Polanyi. History and Theory, v. 8, n. 2, p. 165-212, 1969.

KAPLAN, David. The formal-substantive controversy in economic anthropology: reflections on its wider implications. Southwestern Journal of Anthropology, v. 24, n. 3, p. 228-251, 1968.

KNOWLES, Rob. Political economy from below: communitarian anarchism as a neglected discourse in the histories of economic thought. History of Economics Review, v. 31 , p. $30-47,2000$.

LeCLAIR Jr., Edward. Economic theory and economic anthropology. In: LeCLAIR Jr., E.; SCHNEIDER, H. K. (Ed.). Economic anthropology: readings in theory and analysis. New York: Holt, Rinehart and Winston Inc., 1968. p. 187-207.

, SCHNEIDER, H. K. Introduction. In: LeCLAIR Jr., E.; SCHNEIDER, H. K. (Ed.). Economic anthropology: readings in theory and analysis. New York: Holt, Rinehart and Winston Inc., 1968. p. 1-15.

MACHADO, Nuno. Sociedade vs. Mercado - Notas sobre o pensamento econômico de Karl Polanyi. 2009. Dissertação (Mestrado em Sociologia Económica e das Organizações)-ISEG, Lisboa, 2009.

- Karl Polanyi e a nova sociologia econômica: notas sobre o conceito de (dis)embeddedness. Revista Crítica de Ciências Sociais, n. 90, p. 71-94, 2010.

MALINOWSKI, Bronislaw. Malinowski on the Kula. In: LeCLAIR Jr., E.; SCHNEIDER, H. K. (Ed.). Economic anthropology: readings in theory and analysis. New York: Holt, Rinehart and Winston Inc., 1968. p. 17-39.

NEALE, Walter C. The market in theory and history. In: POLANYI, Karl; ARENSBERG, Conrad; PEARSON, Harry (Ed.). Trade and market in the early empires. Chicago: Henry Regnery, 1957. p. 357-372.

ORLOVE, Benjamin S. Barter and cash sale on Lake Titicaca: a test of competing approaches. Current Anthropology, v. 27, n. 2, p. 85-106, 1986.

PEARSON, Harry. Parsons and Smelser on the economy. In: POLANYI, Karl; ARENSBERG, Conrad; PEARSON, Harry (Ed.). Trade and market in the early empires. Chicago: Henry Regnery, 1957a. p. 307-319. 
PEARSON, Harry. The economy has no surplus: critique of a theory of development. In: POLANYI, Karl; ARENSBERG, Conrad; PEARSON, Harry (Ed.). Trade and market in the early empires. Chicago: Henry Regnery, 1957b. p. 320-341.

POLANYI, Karl. The economy as instituted process. In: DALTON, George (Ed.). Primitive, archaic and modern economies: essays of Karl Polanyi. Boston: Beacon Press, 1968a. p. 139-174.

. Our obsolete market mentality. In: DALTON, George (Ed.). Primitive, archaic and modern economies: essays of Karl Polanyi. Boston: Beacon Press, 1968b. p. 59-77.

. The economistic fallacy. In: POLANYI, Karl; PEARSON, Harry (Ed.). The livelihood of man. New York: Academic Press, 1977a. p. 5-17.

The two meanings of economic. In: POLANYI, Karl; PEARSON, Harry (Ed.). The livelihood of man. New York: Academic Press, 1977b. p. 19-34.

; ARENSBERG, Conrad; PEARSON, Harry. The place of economies in societies. In: DALTON, George (Ed.). Primitive, archaic and modern economies: essays of Karl Polanyi. Boston: Beacon Press, 1968. p. 116-138.

ROBBINS, Lionel. An essay on the nature and significance of economics. London: Macmillan and Co., 1945.

SAHLINS, Marshall. Stone age economics. London: Routledge, 2004.

SCHUMPETER, Joseph. Capitalism, socialism and democracy. London: Routledge, 1992.

STANFIELD, James R. The institutional economics of Karl Polanyi. Journal of Economic Issues, v. 14, n. 3, p. 593-614, 1980.

- The social economics of Karl Polanyi. International Journal of Social Economics, v. 8, n. 5, p. 3-20, 1981.

. Learning from primitive economies. Journal of Economic Issues, v. 16, n. 2, p. $471-479,1982$.

. The economic thought of Karl Polanyi. London: Macmillan, 1986.

. Karl Polanyi and contemporary economic thought. In: POLANYI-LEVITT, Kari (Ed.). The life and work of Karl Polanyi. Montréal: Black Rose Books, 1990. p. 195207.

; CARROLL, Michael C. Social capital, Karl Polanyi, and american social and institutional economics. Journal of Economic Issues, v. 37, n. 2, p. 397-404, 2003.

et al. Karl Polanyi on the limitations of formalism in economics. Research in Economic Anthropology, v. 25, p. 241-266, 2006. 